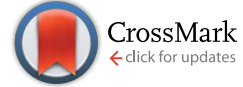

Cite this: RSC Adv., 2015, 5, 937

Received 21st October 2014 Accepted 24th November 2014

DOI: $10.1039 / c 4 r a 12873 g$

www.rsc.org/advances

\section{Mass-analyzed-threshold-ionization (MATI) spectroscopy of 1,2,3-substituted halogenated benzenes via different intermediate vibrational states in the $\mathrm{S}_{1}$ state}

\begin{abstract}
Sascha Krüger, Frank Witte, Jan Helfrich and Jürgen Grotemeyer*
For the first time, two color resonant mass analyzed threshold ionization (MATI) spectroscopy has been applied in order to investigate the ionic properties of 1,3-dichloro-2-fluoro-benzene (1,3,2-DCFB) and 1,3-difluoro-2-chloro-benzene (1,3,2-DFCB) radical cations in their electronic ground state. The ionic ground state of the different samples has been investigated via different $S_{1}$ intermediate states and compared to 1,2,3-trichlorobenzene measured in previous work. Additionally quantum chemical calculations at DFT (density functional theory) and TDDFT (time-dependent density functional theory) level of theory have been performed to support experimental findings. From the MATI spectra the adiabatic ionization energies of 1,3-dichloro-2-fluorobenzene and 1,3-fluoro-2-chlorobenzene could be determined to be $75.242 \pm 6 \mathrm{~cm}^{-1}$ and $75.627 \pm 6 \mathrm{~cm}^{-1}$, respectively. Several vibrational modes of both compounds have been assigned by comparison of the experimental and theoretical results.
\end{abstract}

\section{Introduction}

Halogenated aromatic molecules became a topic of great interest due to their widespread presence in industrial processes and hence presence in the environment as potentially toxic and cancerogenic pollutants. Moreover halogenated benzenes are important model substances to validate theoretical concepts, such as vibronic coupling and others. As one of the spectroscopically best-investigated molecules of all, benzene can serve as an outstanding reference system to study the influence of tailored perturbations, such as careful choice of substitution pattern, to the (ro)vibronic structure. As an immediate effect a shift in transition energies, ionization energy, molecular geometry and vibrational frequencies can be observed. The characteristics of these effects strongly depend on the number, type and localization of the substituents. As the magnitude of these effects are rather small (from a few wavenumbers up to a hundred wavenumbers), high resolution techniques, such as mass analyzed threshold ionization (MATI) or zero kinetic energy (ZEKE) spectroscopy are ideally suited to investigate such phenomena. ${ }^{1-4}$ Chloro- and fluoro-benzenes have been subject to various studies investigating the vibronic properties of the first electronic excited state $\left(\mathrm{S}_{1}\right)$ as well as cationic ground state $\left(D_{0}\right) \cdot{ }^{1,5-13}$ In this paper we will focus particularly on out-of-plane $b_{1}$-symmetric modes. Modes of this

Institut für Physikalische Chemie, Christian-Albrechts-Universität Kiel, Max-Eyth Str. 1, 24118 Kiel, Germany.E-mail: grote@phc.uni-kiel.de symmetry are connected to interesting phenomena observed in a whole variety of halobenzenes. For example, difluorobenzenes exhibit large frequency lowering of $b_{1}\left(b_{3 u}\right.$ under $D_{2 \mathrm{~h}}$ in case of $p$-DFB) symmetric modes in going from $\mathrm{S}_{0}$ to $\mathrm{S}_{1}$ or from $\mathrm{D}_{0}$ to $\mathrm{S}_{1},{ }^{14}$ respectively. The intensity gain of this symmetry forbidden mode was interpreted in terms of the pseudo-Jahn-Teller effect (PJTE). The PJTE is based on the idea that a geometrical distortion blurs the difference in symmetry between two or more electronic states of virtually equal energy. In 1,2,4,5-tetrafluorobenzene $\left(D_{2 \mathrm{~h}}\right)$ it was found that the $\mathrm{b}_{2 \mathrm{~g}}$-symmetric mode 11 shows an unusual strong activity in the form of a long progression $\left(\mathrm{v}_{11}^{2 \mathrm{n}}\right)$. Recent results show that the planarity of this molecule is distorted along the eigenvector of the 11 mode during excitation to ${ }^{1} \mathrm{~B}_{2 \mathrm{u}} \mathrm{S}_{1}$ state. It is an interesting question to elucidate if these phenomena can be extended to further congeners and identified as a general feature. In particular in the case of the molecular geometry change it is crucial to determine the involved vibrational modes and participating electronic states. For this purpose, the experimental data are compared to theoretical calculations, which enable the possibility of assigning the observed vibrational modes. In this paper we present mass-selected two color two photon Resonance Enhanced Multi Photon Ionization (2C2P-REMPI) spectra of the $\mathrm{S}_{1} \leftarrow \mathrm{S}_{0}$ transition and MATI spectra via different $\mathrm{S}_{1}$-intermediate states of 1,3-dichloro-2-fluorobenzene and 1,3-dichloro-2fluorobenzene. Some assignments of 1,2,3-trichlorobenzene reported previously ${ }^{1}$ were reconsidered and compared to the newly gained knowledge. 


\section{Experimental setup}

The experimental setup consists of a homemade time-of-flight (TOF) mass spectrometer as described in detail previously. ${ }^{\mathbf{1 , 1 5}, 16}$ Briefly, the spectrometer consists of a standard second order corrected reflectron time-of-flight mass spectrometer equipped with single stage ion source. The laser system used for excitation and ionization consists of two dye lasers (Laser Analytical Systems LDL 205, Lambda Physics FL 3002). Each dye laser is pumped by a dedicated Nd:YAG laser (Lumonics HY-1200, Continuum Surelite II). A Quantum Composers 9600+ delay pulse generator fed by an external clock operated at $10 \mathrm{~Hz}$ controls flash lamp and Q-switch delays. The output of each dye laser is frequency-doubled by a BBO-I crystal yielding tunable ranges from 245 to $285 \mathrm{~nm}$. Wavelength calibration of both dye lasers is performed by recording an optogalvanic spectrum with a neon hollow cathode lamp yielding accuracy better than $2 \mathrm{~cm}^{-1}$. Initially a supersonic molecular beam of sample molecules and seed gas (argon) with a backing pressure of approximately 2 bar is expanded via a pulsed jet valve (General Valves Series 9) into the ion source. To obtain a sufficient vapor pressure the sample is heated to approximately $80{ }^{\circ} \mathrm{C}$. Excitation or ionization is accomplished by multi photon absorption under field-free conditions. In the MATI modus, promptly generated ions are discriminated against Rydberg neutrals through the application of a weak electrical field of $1-2 \mathrm{~V} \mathrm{~cm}^{-1}$ by a subsequent delay ( $\left.\sim 100 \mathrm{~ns}\right)$ to multi-photon excitation. Finally, a high voltage pulse $\left(890 \mathrm{~V} \mathrm{~cm}^{-1}\right)$ switched by a Behlke HS56-01 fast thyristor ionizes the Rydberg neutrals and accelerates them into the mass spectrometer. In REMPI modus, the generated ions are accelerated directly into the TOF without the retarding field. The ion signal is detected by a conventional dual micro-channel-plate detector and transferred to a LeCroy 534M digital oscilloscope. A computer, linked to the oscilloscope by a GPIB connection performs the data acquisition and processing. The 123-DCFB was purchased from Aldrich, 126-DFCB from ABCR and were used without further purification.

\section{Quantum-chemical calculations}

Quantum chemical calculations were performed in order to assign the observed vibrational bands and to support the experimental findings. The software package Turbomole $e^{17-20}$ was used for all quantum chemical calculations. Geometry optimizations and subsequent frequency analyses for molecules in the electronic ground state $\left(\mathrm{S}_{0}\right)$ and the cationic ground state $\left(\mathrm{D}_{0}\right)$ were conducted at the density functional theory (DFT) level of theory with both the gradient corrected functional BP86 ${ }^{21 a}$ and the hybrid functional B3LYP. ${ }^{21 b}$ The triple basis set TZVPP $^{21 c}$ has been applied to all DFT calculations. Calculations for the $S_{1}$ were done analogously using the time dependent density functional theory (TDDFT). For comparison reasons, geometry calculations and frequency analyses were also treated at the coupled cluster (CC2) level of theory for the $S_{0^{-}}$and $S_{1^{-}}$ state using the Ahlrichs basis set cc-pVTZ. ${ }^{\mathbf{2 1 d}}$ The nomenclature used for assignment of vibrational bands is according to
Varsanyi and Szoke, ${ }^{22}$ which is derived from Wilson's notation of the Benzene modes. ${ }^{23}$

We refrained from the use of scaling factors to fit the calculated frequencies.

\section{Experimental results}

\subsection{1,3-Dichloro-2-fluorobenzene (1,3,2-DCFB)}

4.1.1. REMPI spectrum. According to electric dipole selection rules the transition to first excited singlet state ${ }^{1} \mathrm{~B}_{2} \mathrm{~S}_{1}\left(\pi^{*} \leftarrow\right.$ $\pi$ ) in 1,3,2-DCFB is allowed ( $y$-polarized). For benzene, the corresponding transition $\mathrm{A}^{1} \mathrm{~B}_{2 \mathrm{u}} \leftarrow \mathrm{X}^{1} \mathrm{~A}_{1 \mathrm{~g}}$ is dipole forbidden under $D_{6 \mathrm{~h}}$ symmetry. The reduced symmetry in 1,3,2-DCFB $\left(C_{2 \mathrm{v}}\right)$ leads to an electronically as well as vibronically allowed transition. Starting from the premise that the molecules are sufficiently cooled with regards to their degrees of freedom, only total symmetric $\left(\mathrm{a}_{1}\right)$ vibrations are allowed according to the Franck-Condon (FC) principle. Due to vibronic coupling to intensive, nearby states, vibrations of $\mathrm{a}_{2}$ and $\mathrm{b}_{2}$ symmetry can gain intensity as well. The REMPI spectrum shown in Fig. 1 in units of internal energy could be recorded in the range up to $1300 \mathrm{~cm}^{-1}$. The excitation energy of the first excited state $S_{1}$ could be determined for the first time to be $36460 \pm 2 \mathrm{~cm}^{-1}$.

Normal coordinate analysis for 1,3,2-DCFB yields following distribution of fundamental modes under $C_{2 \mathrm{v}}$ symmetry: $\Gamma_{\mathrm{vib}}=$ $11 \times a_{1}, 10 \times b_{2}, 3 \times a_{2}, 6 \times b_{1}$. Clearly, the spectrum is dominated by the total symmetric modes $1^{1}\left(565 \mathrm{~cm}^{-1}\right)$ and $18 \mathrm{a}$ $\left(977 \mathrm{~cm}^{-1}\right)$. Moreover the $\mathrm{a}_{1}$-symmetric modes $9 \mathrm{a}^{1}, 6 \mathrm{a}^{1}, 7 \mathrm{a}^{1}, 12^{1}$ $\left(186 \mathrm{~cm}^{-1}, 349 \mathrm{~cm}^{-1}, 792 \mathrm{~cm}^{-1}, 1104 \mathrm{~cm}^{-1}\right)$ could be identified with lower intensity. With $16 \mathrm{a}^{1}\left(360 \mathrm{~cm}^{-1}\right)$ also an $\mathrm{a}_{2}$-symmetric mode could be assigned. As expected, no modes of $b_{1}$-symmetry could be assigned to the spectrum in accordance with selection rules. Particular attention should be paid to the low frequency band at $120 \mathrm{~cm}^{-1}$. A band with such a low frequency can with certainty be assigned to an out-of-plain mode. Based on correlation with MATI spectra we assigned the first even overtone of the $b_{1}$-symmetric mode $17 \mathrm{~b}$ to this band. The frequency of 52 $\mathrm{cm}^{-1}$ calculated with the coupled cluster method is in reasonable agreement with the experimental value for the half of the overtone for $17 \mathrm{~b}^{2}$. The bands at $247 \mathrm{~cm}^{-1}\left(15^{1}\right), 337 \mathrm{~cm}^{-1}\left(6 \mathrm{~b}^{1}\right)$, $500 \mathrm{~cm}^{-1}\left(3^{1}\right)$ and $1236 \mathrm{~cm}^{-1}\left(18 \mathrm{~b}^{1}\right)$ were assigned to $\mathrm{b}_{2^{-}}$ symmetric modes. The latter two experimental values are in excellent agreement with both calculated values (TDDFT, CC2) for the first excited singlet state of 1,2,3-DCFB. Comparing the calculated values for the $15^{1}$ and $6 \mathrm{~b}^{1}$ mode a major deviation becomes apparent, just like in the case of $17 \mathrm{~b}$. All performed calculations show good agreement with the experiment for the modes $9 \mathrm{a}^{1}, 6 \mathrm{a}^{1}, 1^{1}, 7 \mathrm{a}^{1}, 18 \mathrm{a}^{1}, 12^{1}, 16 \mathrm{a}^{1}$, whereas the best results were obtained with the CC2 level of theory (see Table 1).

4.1.2. MATI spectra. The MATI spectra via the $S_{1}$ intermediate states $0^{0}, 17 \mathrm{~b}^{1}, 9 \mathrm{a}^{1}, 1^{1}$ are shown in Fig. 2 . The origin of the $\mathrm{D}_{0}\left({ }^{2} \mathrm{~B}_{1}\right)$ state and with that the adiabatic ionization energy was found to be $75.242 \pm 6 \mathrm{~cm}^{-1}(9.3288 \pm 0.0007 \mathrm{eV})$. This value is in good accordance with the previously by conventional photoelectron spectroscopy determined value of $9.32 \pm 0.02$ $\mathrm{eV}^{25}$ 


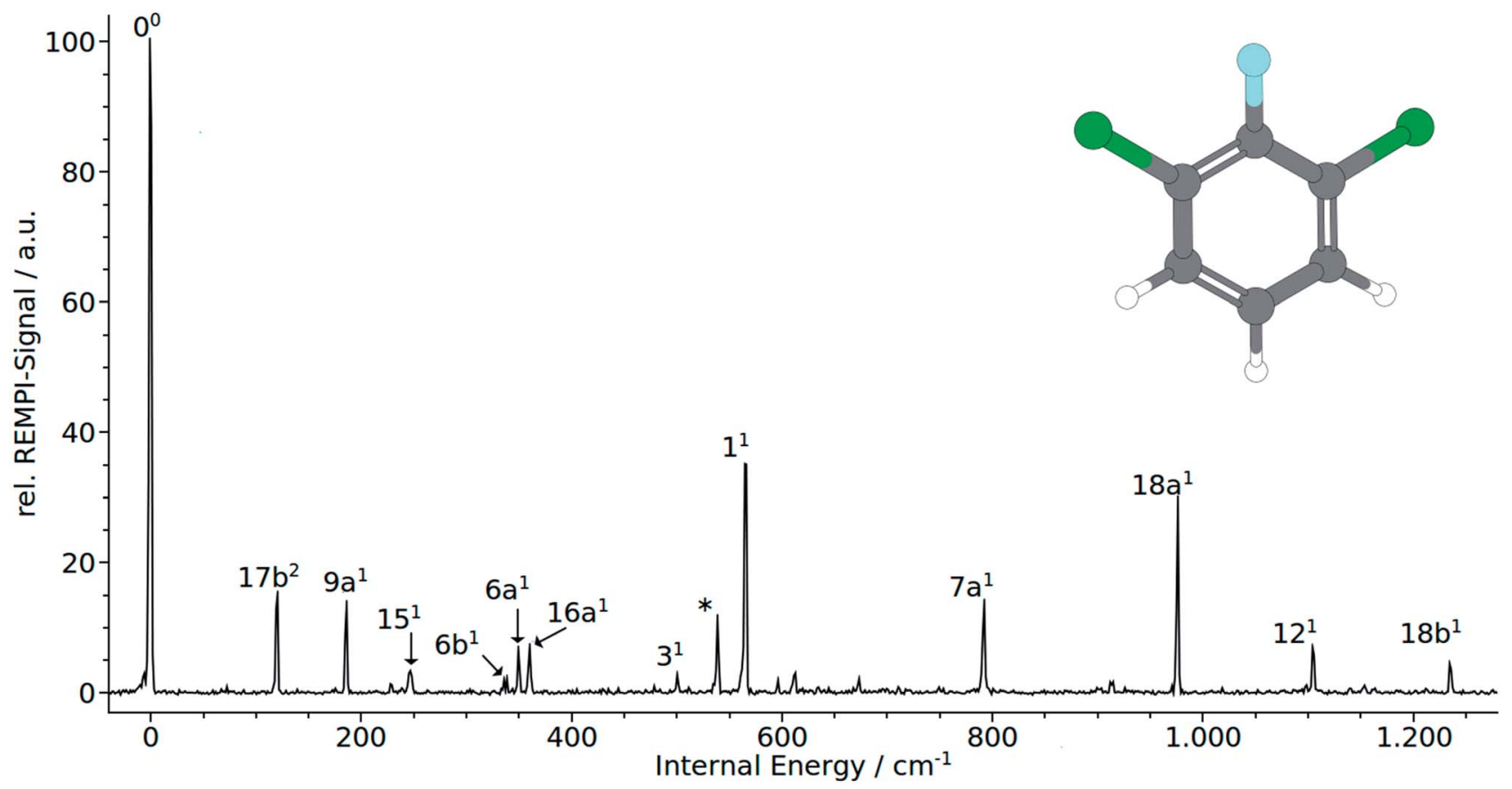

Fig. $1\left(1+1^{\prime}\right)$ REMPI spectrum of 1,3-dichloro-2-fluoro-benzene (1,3,2-DCFB).

Table 1 Comparison experimental and calculated normal modes observed in the $S_{0}, S_{1}$ and $D_{0}$ state of 1,3,2 DCFB

\begin{tabular}{|c|c|c|c|c|c|c|c|c|c|c|c|c|}
\hline \multicolumn{6}{|l|}{$\mathrm{S}_{0}\left(C_{2 \mathrm{v}}\right)$} & \multirow{2}{*}{$\frac{\mathrm{S}_{1}}{\text { exp. }}$} & \multirow{2}{*}{$\frac{\left(C_{2 \mathrm{v}}\right)}{\text { B3LYP }}$} & \multirow{2}{*}{$\frac{\left(C_{2 \mathrm{v}}\right)}{\text { BP86 }}$} & \multirow{2}{*}{$\frac{\left(C_{\mathrm{S}}\right)}{\mathrm{CC} 2}$} & \multirow{2}{*}{$\frac{\mathrm{D}_{0}}{\text { exp. }}$} & \multicolumn{2}{|l|}{$\left(C_{2 \mathrm{v}}\right)$} \\
\hline Wilson & Sym. & exp. & B3LYP & BP86 & $\mathrm{CC} 2$ & & & & & & B3LYP & BP86 \\
\hline $9 a$ & $a_{1}$ & $256^{a}$ & 192 & 186 & 189 & 186 & 241 & 232 & 183 & 190 & 195 & 189 \\
\hline $6 a$ & $a_{1}$ & $376^{a}$ & 379 & 369 & 380 & 349 & 355 & 361 & 343 & 361 & 381 & 372 \\
\hline 1 & $a_{1}$ & $597^{a}$ & 601 & 584 & 596 & 565 & 538 & 522 & 558 & 578 & 603 & 586 \\
\hline $7 a$ & $a_{1}$ & $803^{a}$ & 839 & 813 & 829 & 792 & 831 & 815 & 791 & 798 & 820 & 797 \\
\hline $18 \mathrm{a}$ & $a_{1}$ & $1058^{a}$ & 1092 & 1061 & 1080 & 977 & 1013 & 998 & 991 & & 1047 & 1027 \\
\hline 12 & $a_{1}$ & $1112^{a}$ & 1116 & 1083 & 1124 & 1104 & 1077 & 1046 & 1079 & & 1143 & 1104 \\
\hline 13 & $a_{1}$ & $1205^{a}$ & 1277 & 1240 & 1277 & & 1314 & 1320 & 1242 & & 1339 & 1295 \\
\hline $19 \mathrm{a}$ & $a_{1}$ & $1462^{a}$ & 1490 & 1444 & 1485 & & 1213 & 1229 & 1383 & & 1459 & 1412 \\
\hline $8 \mathrm{a}$ & $a_{1}$ & $1572^{a}$ & 1613 & 1564 & 1608 & & 1509 & 1476 & 1512 & & 1618 & 1567 \\
\hline $20 \mathrm{a}$ & $a_{1}$ & $3084^{a}$ & 3189 & 3119 & 3220 & & 3159 & 3080 & 3210 & & 3197 & 3126 \\
\hline 2 & $a_{1}$ & & 3212 & 3142 & 3243 & & 3220 & 3147 & 3246 & & 3218 & 3147 \\
\hline $10 \mathrm{a}$ & $a_{2}$ & $215^{a, b}$ & 208 & 201 & 207 & & 120 & 123 & 71 & 174 & 180 & 173 \\
\hline $16 a$ & $a_{2}$ & $530^{a, b}$ & 553 & 534 & 518 & 360 & 458 & 495 & 313 & 512 & 498 & 476 \\
\hline $17 \mathrm{a}$ & $\mathrm{a}_{2}$ & $894^{a}$ & 921 & 876 & 890 & & 1045 & 1060 & 616 & & 936 & 897 \\
\hline $17 \mathrm{~b}$ & $b_{1}$ & $115^{a, b}$ & 107 & 103 & 107 & $60^{c}$ & 31 & 38 & 52 & 95 & 88 & 85 \\
\hline $10 \mathrm{~b}$ & $b_{1}$ & $260^{a, b}$ & 282 & 271 & 278 & $270^{c}$ & 263 & 259 & 178 & 264 & 274 & 265 \\
\hline $16 \mathrm{~b}$ & $\mathrm{~b}_{1}$ & $513^{a}$ & 533 & 512 & 542 & & 502 & 454 & 364 & 452 & 455 & 441 \\
\hline 4 & $b_{1}$ & $705^{a}$ & 732 & 699 & 680 & & 766 & 755 & 460 & 732 & 743 & 715 \\
\hline 11 & $\mathrm{~b}_{1}$ & $770^{a}$ & 794 & 758 & 771 & & 847 & 827 & 601 & 678 & 826 & 792 \\
\hline 5 & $b_{1}$ & $965^{a}$ & 983 & 937 & 949 & & 1004 & 966 & 782 & & 1009 & 966 \\
\hline 15 & $\mathrm{~b}_{2}$ & $279^{a}$ & 258 & 248 & 252 & 247 & 62 & 61 & 227 & 242 & 233 & 253 \\
\hline $6 b$ & $\mathrm{~b}_{2}$ & $401^{a}$ & 404 & 393 & 401 & 337 & 202 & 209 & 319 & 331 & 300 & 331 \\
\hline 3 & $\mathrm{~b}_{2}$ & $539^{a}$ & 545 & 528 & 538 & 500 & 500 & 498 & 519 & 471 & 513 & 504 \\
\hline $7 \mathrm{~b}$ & $\mathrm{~b}_{2}$ & $829^{a}$ & 798 & 779 & 810 & & 698 & 683 & 759 & 827 & 812 & 796 \\
\hline $9 b$ & $\mathrm{~b}_{2}$ & $1154^{a}$ & 1180 & 1145 & 1170 & & 1177 & 1144 & 1105 & & 1083 & 1104 \\
\hline $18 \mathrm{~b}$ & $\mathrm{~b}_{2}$ & $1205^{a, b}$ & 1233 & 1193 & 1223 & 1236 & 1250 & 1185 & 1170 & & 1330 & 1192 \\
\hline 14 & $\mathrm{~b}_{2}$ & $1255^{a}$ & 1313 & 1322 & 1421 & & 1413 & 1360 & 1497 & & 1226 & 1296 \\
\hline $19 b$ & $\mathrm{~b}_{2}$ & $1446^{a}$ & 1481 & 1432 & 1465 & & 1446 & 1407 & 1389 & & 1514 & 1466 \\
\hline $8 b$ & $\mathrm{~b}_{2}$ & $1583^{a}$ & 1615 & 1566 & 1608 & & 1574 & 1545 & 1683 & & 1371 & 1384 \\
\hline $20 \mathrm{~b}$ & $\mathrm{~b}_{2}$ & $3084^{a}$ & 3207 & 3137 & 3235 & & 3188 & 3177 & 3141 & & 3215 & 3144 \\
\hline
\end{tabular}

${ }^{a}$ IR-band.$^{24}{ }^{b}$ From combination band. ${ }^{c}$ From overtone. 


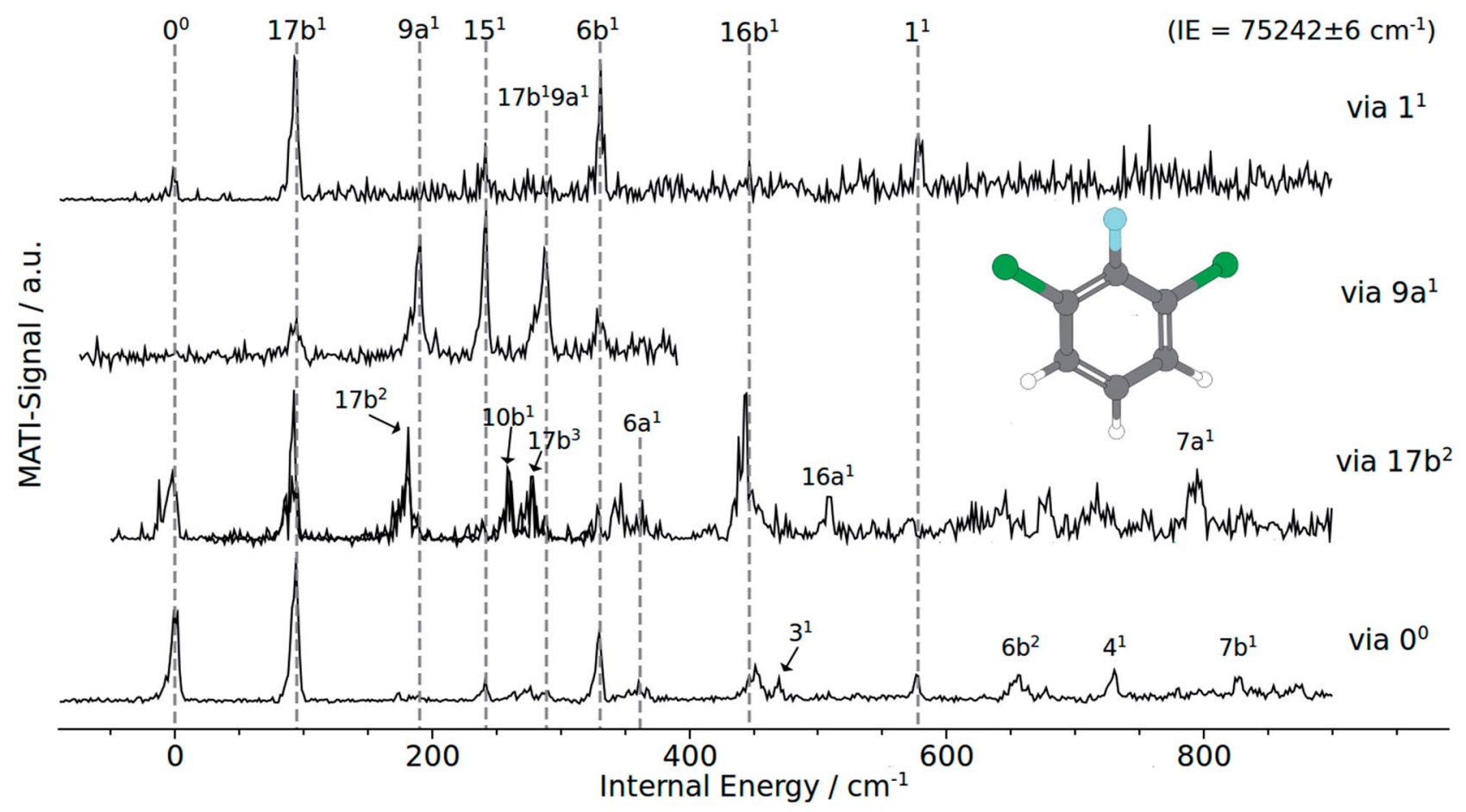

Fig. 2 MATI spectra of 1,3,2-DCFB of different vibrational intermediate states of the first excited electronic state: (a) via $1^{1}$, (b) via $9 a^{1}$, (c) via $17 b^{2}$, (d) via the electronic origin $\left(0^{\circ}\right)$.

Besides the $0^{0}$ transition, the MATI spectrum obtained via the electronic origin exhibits several more additional resonances. The most prominent peak in the spectrum is the band assigned to the $17 \mathrm{~b}$ mode, which is constituting a violation of the $\Delta v=0$ propensity rule. Additionally, the mode $17 \mathrm{~b}^{1}$ at 95 $\mathrm{cm}^{-1}$ appears as a combination band $\left(17 \mathrm{~b}^{1} 9 \mathrm{a}^{1}\right)$ at $288 \mathrm{~cm}^{-1}$. Moreover the spectrum is conspicuously rich in $b_{1}$-symmetric modes. In addition to $17 \mathrm{~b}^{1}$ we assigned the $10 \mathrm{~b}^{1}\left(264 \mathrm{~cm}^{-1}\right)$, $16 \mathrm{~b}^{1}\left(452 \mathrm{~cm}^{-1}\right), 11^{1}\left(678 \mathrm{~cm}^{-1}\right)$ and $4^{1}\left(732 \mathrm{~cm}^{-1}\right)$. Another outof-plane vibration $\left(10 \mathrm{a}^{1}\right)$ with $\mathrm{a}_{2}$-symmetry and low intensity has been assigned to the band at $174 \mathrm{~cm}^{-1}$. The bands at $361 \mathrm{~cm}^{-1}$, $578 \mathrm{~cm}^{-1}$ have been assigned to the total symmetric modes $6 \mathrm{a}^{1}$ and $1^{1}$, respectively. $b_{2}$ symmetric modes were identified at 242 $\mathrm{cm}^{-1}\left(15^{1}\right), 331 \mathrm{~cm}^{-1}\left(6 \mathrm{~b}^{1}\right), 471 \mathrm{~cm}^{-1}\left(3^{1}\right)$ and $827 \mathrm{~cm}^{-1}\left(7 \mathrm{~b}^{1}\right)$. The band at $657 \mathrm{~cm}^{-1}$ fits the overtone $6 \mathrm{~b}^{1}$.

The MATI spectrum obtained via the $\mathrm{S}_{1} 17 \mathrm{~b}^{2}$ shows a short, three-membered regular progression with transitions corresponding to the excitation of one, two and three quanta. In contradiction to the $\Delta v=0$ propensity rule, the band labeled $17 \mathrm{~b}^{1}$ is the most prominent peak in the spectrum. It is notable that the $17 \mathrm{~b}$ mode also appears in the combination bands $17 \mathrm{~b}^{1} 9 \mathrm{a}^{1}\left(288 \mathrm{~cm}^{-1}\right)$ and $16 \mathrm{~b}^{1} 6 \mathrm{~b}^{1}\left(423 \mathrm{~cm}^{-1}\right)$. Also apparent is the richness in $b_{1}$-symmetric modes, first and foremost the intense $16 \mathrm{~b}^{1}\left(448 \mathrm{~cm}^{-1}\right)$, but also the $10 \mathrm{~b}^{1}\left(264 \mathrm{~cm}^{-1}\right), 11^{1}(680$ $\left.\mathrm{cm}^{-1}\right), 4^{1}\left(728 \mathrm{~cm}^{-1}\right)$. The MATI spectrum obtained via the $\mathrm{S}_{1} 9 \mathrm{a}^{1}$ mode also shows a breakdown of the $\Delta v=0$ propensity rule. Not the vertical transition into the $\mathrm{D}_{0} 9 \mathrm{a}^{1}$ state is the dominating one, but the band at $242 \mathrm{~cm}^{-1}\left(15^{1}\right)$. In addition the $17 \mathrm{~b}$ mode appears again, also as a combination in $17 \mathrm{~b}^{1} 9 \mathrm{a}^{1}$. A further band at $331 \mathrm{~cm}^{-1}$ could be identified with $6 \mathrm{~b}^{1}$. The measured values are in good accordance with the calculated values (195 and 189 $\mathrm{cm}^{-1}$ for the $9 \mathrm{a}^{1}, 233$ and $253 \mathrm{~cm}^{-1}$ for the $15^{1}$ and also 300 and $331 \mathrm{~cm}^{-1}$ for the $\left.6 \mathrm{~b}^{1}\right)$.

The MATI spectrum via $\mathrm{S}_{1} 1^{1}$ continues the series of MATI spectra characterized by a breakdown of the $\Delta v=0$ propensity rule in favor for the vibronic transition into the $\mathrm{D}_{0} 17 \mathrm{~b}^{1}$ state. Further active modes that could be assigned in the recorded range up to $750 \mathrm{~cm}^{-1}$ are the $15^{1}\left(241 \mathrm{~cm}^{-1}\right), 6 \mathrm{~b}^{1}\left(331 \mathrm{~cm}^{-1}\right)$ and $1^{1}\left(578 \mathrm{~cm}^{-1}\right)$. The experimentally determined frequency for the $1^{1}$ mode is in good accordance with the calculated values of 578 $\mathrm{cm}^{-1}$ or $603 \mathrm{~cm}^{-1}$ respectively. It should be noticed that, owing to the heavy substituents, the displacement pattern of the 'ringbreathing-mode' shows a striking deviation from the original benzene pattern. It resembles clearly the pattern of mode $6 \mathrm{a}$ found for benzene. The assignment of the band at $578 \mathrm{~cm}^{-1}$ to the mode $6 \mathrm{a}$ is excluded since it was already doubtlessly assigned to the band at $361 \mathrm{~cm}^{-1}$.

\subsection{1,3-Difluoro-2-chloro-benzene (1,3,2-DFCB)}

4.2.1. REMPI spectrum. $1,3,2-\mathrm{DFCB}$ belongs to $C_{2 \mathrm{v}}$ point group and has a dipole allowed transition to the ${ }^{1} \mathrm{~A}_{1} \mathrm{~S}_{1}\left(\pi^{*} \leftarrow \pi\right)$ first excited state. According to FC-principle only transitions in total symmetric $\left(a_{1}\right)$ modes are allowed, $b_{1}$ and $b_{2}$ can gain intensity due to vibronic coupling mechanism, $\mathrm{a}_{2}$ modes are symmetry forbidden. The REMPI spectrum shown in Fig. 3 in units of internal energy could be recorded in the range up to 800 $\mathrm{cm}^{-1}$. The excitation energy of the first excited state $\mathrm{S}_{1}$ could be determined for the first time to be $37449 \pm 2 \mathrm{~cm}^{-1}$. 


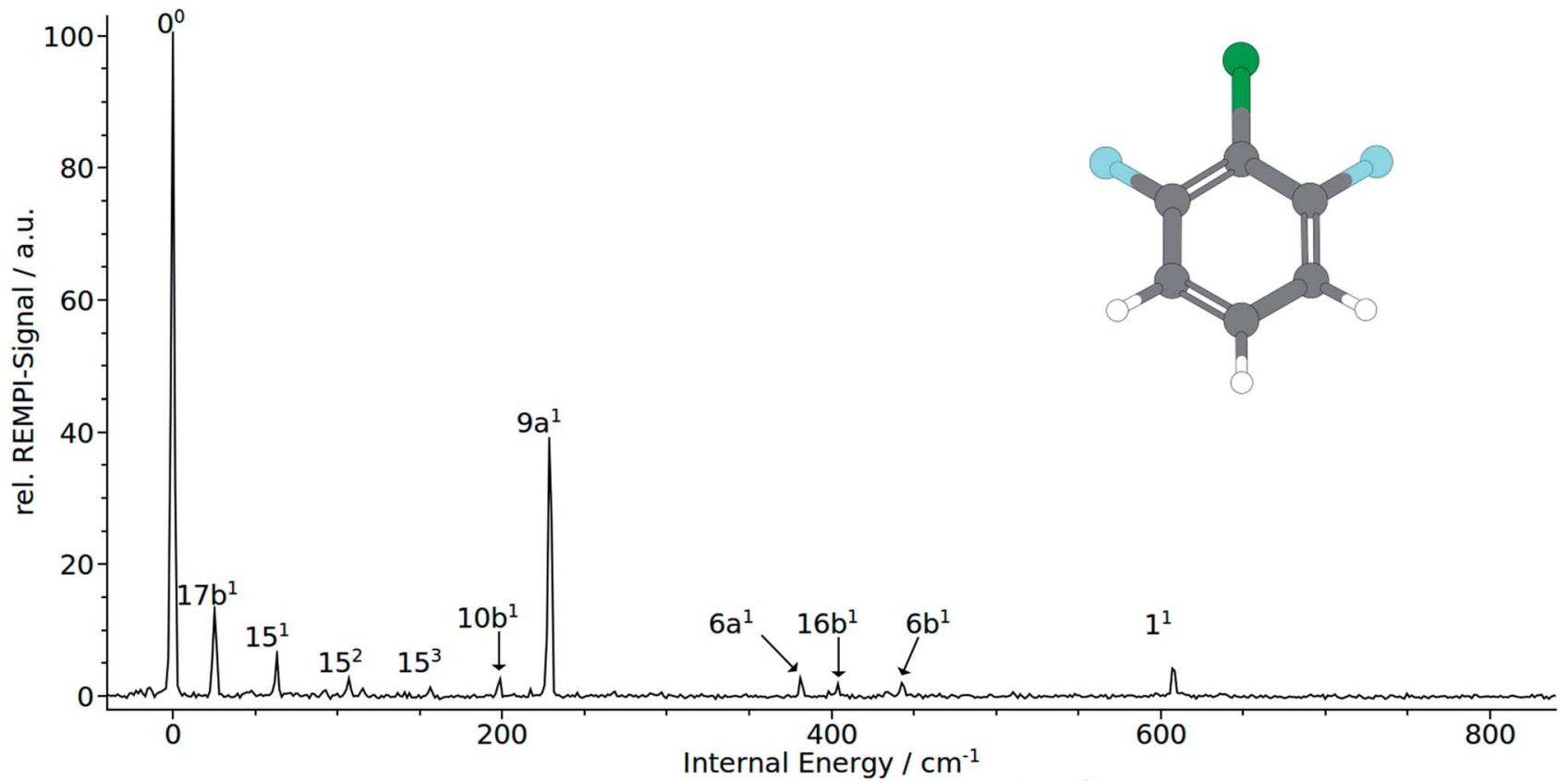

Fig. $3\left(1+1^{\prime}\right)$ REMPI spectrum of 1,3-difluoro-2-chloro-benzene (1,3,2-DFCB).

The electronic origin and the total symmetric mode $9 a^{1}$ at $228 \mathrm{~cm}^{-1}$ dominates clearly the measured REMPI spectrum. It should be noted that the remaining bands at $381 \mathrm{~cm}^{-1}$ and 607 $\mathrm{cm}^{-1}$ that were both assigned to the total symmetric modes $6^{1}$ and $1^{1}$, respectively. Quite unusual for total symmetric modes we found poor consistency between calculated and observed bands: calculation substantially underestimate the $6 \mathrm{a}^{1}$ and $1^{1}$ with $188 \mathrm{~cm}^{-1}$ to $202 \mathrm{~cm}^{-1}$ and $488 \mathrm{~cm}^{-1}$ to $517 \mathrm{~cm}^{-1}$, respectively. The $9 \mathrm{a}^{1}$ has been overestimated with $364 \mathrm{~cm}^{-1}$ to $374 \mathrm{~cm}^{-1}$. Nevertheless the correlation with MATI spectra backups the assignment of the total symmetric modes. Moreover, the calculations suggest the mode $7 \mathrm{a}^{1}$, that cannot be seen in the spectrum, to appear in the spectrum between $710 \mathrm{~cm}^{-1}$ and $750 \mathrm{~cm}^{-1}$. As expected, no modes of $\mathrm{a}_{2}$ symmetry could be assigned to the spectrum in accordance with selection rules. In contrast to 1,2,3-TCB and 1,3,2-DCFB, transitions to $b_{1}$ symmetric modes are allowed in 1,3,2-DFCB. The bands at 25 , 98 and $404 \mathrm{~cm}^{-1}$ could be identified with the $\mathrm{b}_{1}$-symmetric modes $17 \mathrm{~b}^{1}, 10 \mathrm{~b}^{1}$ and $16 \mathrm{~b}^{1}$. In this case, the calculated frequencies are in good agreement with the observed ones. The

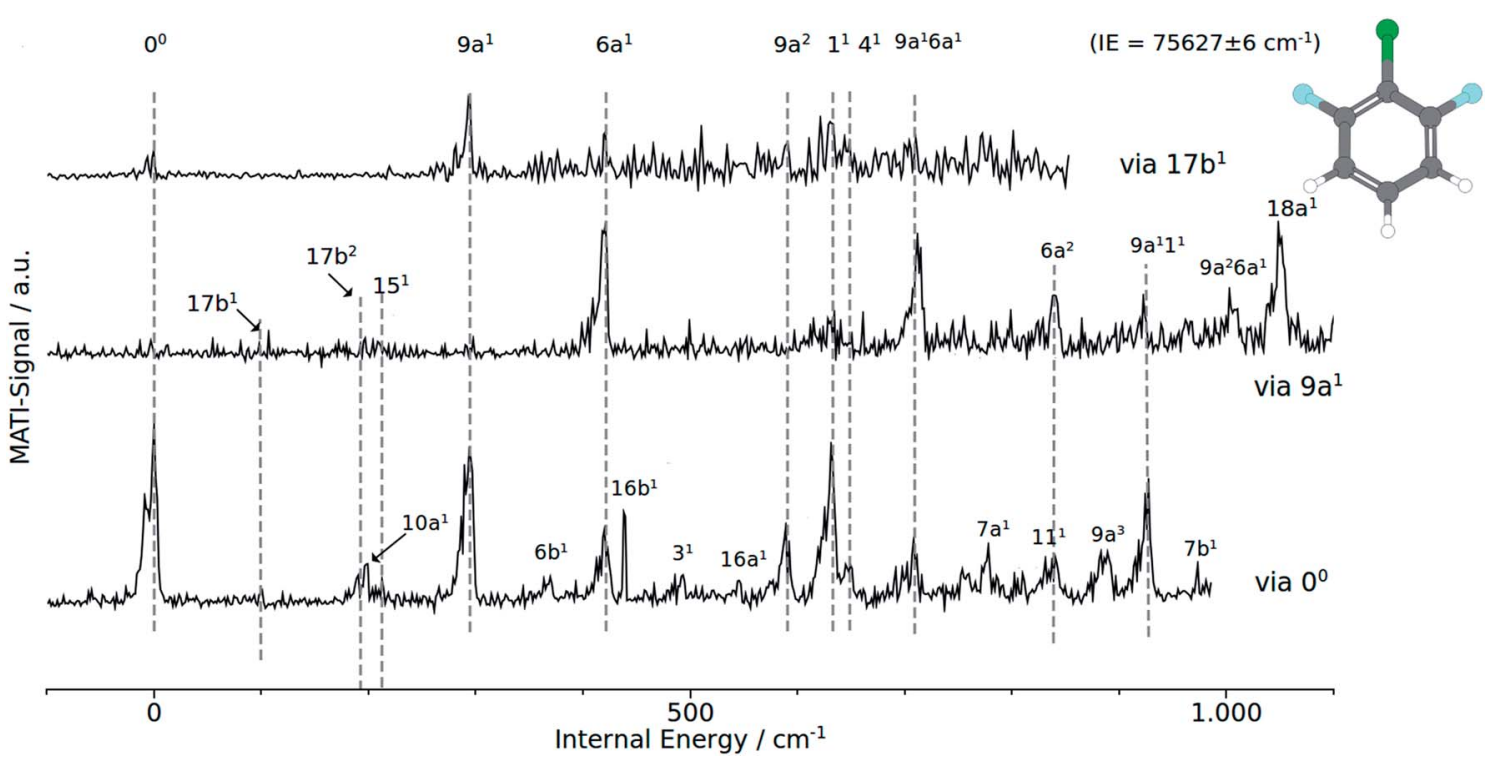

Fig. 4 MATI spectra of 1,2,6 DCFB of different vibrational intermediate states of the first excited electronic state: (a) via $9 a^{1}$, (b) via $17 b^{2}$, (c) via the electronic origin $\left(0^{\circ}\right)$. 


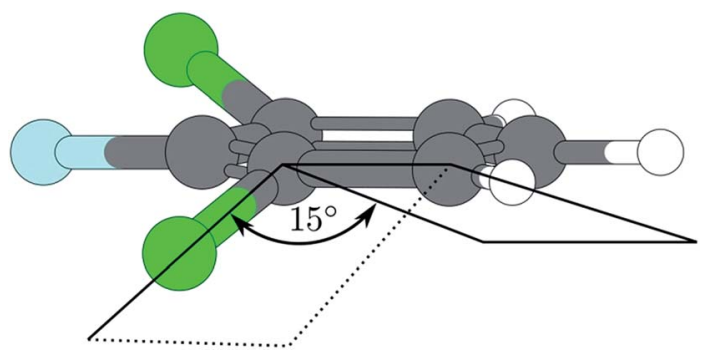

Fig. 5 Excited state geometry of 1,3,2-DCFB obtained by CC2optimization.

$17 \mathrm{~b}^{1}$ has been predicted to appear between $31 \mathrm{~cm}^{-1}$ and 51 $\mathrm{cm}^{-1}$, the $10 \mathrm{~b}^{1}$ between $176 \mathrm{~cm}^{-1}$ and $215 \mathrm{~cm}^{-1}$ and the $16 \mathrm{~b}^{1}$ between $351 \mathrm{~cm}^{-1}$ and $428 \mathrm{~cm}^{-1}$. With $15^{1}$ and $6 \mathrm{~b}^{1}$ two $\mathrm{a}_{2^{-}}$ symmetric modes could be assigned. Noteworthy is the appearance of the 15 mode as a short, three-membered progression of overtones $\left(15^{1}, 15^{2}, 15^{3}\right)$. The measured frequencies of $443 \mathrm{~cm}^{-1}$ for $6 \mathrm{~b}^{1}$ and $63 \mathrm{~cm}^{-1}$ for $15^{1}$ are well reproduced by the B3LYP calculation with 439 and $64 \mathrm{~cm}^{-1}$. The BP86 calculation predicts the $15^{1}$ correctly with $67 \mathrm{~cm}^{-1}$, while it slightly overestimates the $6 \mathrm{~b}^{1}$ with $463 \mathrm{~cm}^{-1}$. The CC2 calculation gives good results in predicting the $6 b^{1}$ with 439 $\mathrm{cm}^{-1}$, while it overestimates the $15^{1}$ with $154 \mathrm{~cm}^{-1}$.

4.2.2. MATI spectra. The MATI spectra via the $\mathrm{S}_{1}$ intermediate states $0^{0}, 17 \mathrm{~b}^{1}, 9 \mathrm{a}^{1}$ are shown in Fig. 4 . The origin of the $\mathrm{D}_{0}\left({ }^{2} \mathrm{~B}_{1}\right)$ state and with that the adiabatic ionization energy was found to be $75.627 \pm 6 \mathrm{~cm}^{-1}(9.3765 \pm 0.0007 \mathrm{eV})$. This value is in good accordance the previously by photoelectron spectroscopy determined value of $9.37 \pm 0.02 \mathrm{eV}^{25}$

In accordance with the $\Delta v=0$ propensity rule, the MATI spectrum obtained via the electronic origin is dominated by the $0^{0}$-band. Furthermore the spectrum is characterized by strong activity of the two total symmetric modes $9 \mathrm{a}^{1}$ and $6 \mathrm{a}^{1}$. Within the recorded range of $1000 \mathrm{~cm}^{-1}$, the spectrum exhibits a progression in 9a composed of the first three overtones $9 \mathrm{a}^{1}$ (293 $\left.\mathrm{cm}^{-1}\right), 9 \mathrm{a}^{2}\left(588 \mathrm{~cm}^{-1}\right)$ and $9 \mathrm{a}^{3}\left(882 \mathrm{~cm}^{-1}\right)$. The 6a appears as ground vibration $6 \mathrm{a}^{1}\left(418 \mathrm{~cm}^{-1}\right)$, first overtone $6 \mathrm{a}^{2}\left(839 \mathrm{~cm}^{-1}\right)$ as well as combination vibration $9 \mathrm{a}^{1} 6 \mathrm{a}^{1}\left(706 \mathrm{~cm}^{-1}\right)$.

Additionally we assigned the band at $925 \mathrm{~cm}^{-1}$ to a combination band of modes $9 \mathrm{a}^{1} 1^{1}$. The relative intensive band at 630 $\mathrm{cm}^{-1}$ has been identified with the mode $1^{1}$. The shoulder at 649 $\mathrm{cm}^{-1}$ in the peak labeled with $1^{1}$ has been assigned to the mode $4^{1}$. Exhibiting a similar weak intensity as the $4^{1}$, another $b_{1^{-}}$symmetrical mode $\left(7 \mathrm{a}^{1}\right)$ could be identified at $778 \mathrm{~cm}^{-1}$. In the view of previous work, ${ }^{1}$ the assignment of the bands at $95 \mathrm{~cm}^{-1}$

Table 2 Comparison experimental and calculated normal modes observed in the $S_{0}, S_{1}$ and $D_{0}$ state of 1,3,2 DFCB

\begin{tabular}{|c|c|c|c|c|c|c|c|c|c|c|c|c|}
\hline \multicolumn{6}{|l|}{$\mathrm{S}_{0}\left(C_{2 \mathrm{v}}\right)$} & \multirow{2}{*}{$\frac{S_{1}}{\text { exp. }}$} & \multirow{2}{*}{$\frac{\left(C_{2 \mathrm{v}}\right)}{\text { B3LYP }}$} & \multirow{2}{*}{$\frac{\left(C_{2 \mathrm{v}}\right)}{\text { BP86 }}$} & \multirow{2}{*}{$\frac{\left(C_{\mathrm{S}}\right)}{\mathrm{CC} 2}$} & \multirow{2}{*}{$\frac{D_{0}}{\text { exp. }}$} & \multicolumn{2}{|l|}{$\left(C_{2 \mathrm{v}}\right)$} \\
\hline Wilson & Sym. & exp. & B3LYP & BP86 & $\mathrm{CC} 2$ & & & & & & B3LYP & BP86 \\
\hline $9 a$ & $a_{1}$ & & 301 & 290 & 295 & 228 & 374 & 364 & 367 & 293 & 304 & 294 \\
\hline $6 a$ & $a_{1}$ & & 437 & 425 & 436 & 381 & 198 & 202 & 188 & 418 & 435 & 422 \\
\hline 1 & $\mathrm{a}_{1}$ & & 617 & 602 & 618 & 607 & 517 & 500 & 488 & 630 & 636 & 620 \\
\hline $7 a$ & $a_{1}$ & & 783 & 760 & 776 & & 748 & 729 & 713 & 778 & 784 & 761 \\
\hline $19 a$ & $a_{1}$ & & 1072 & 1142 & 1124 & & 1506 & 1462 & 1360 & & 1360 & 1318 \\
\hline $18 \mathrm{a}$ & $\mathrm{a}_{1}$ & & 1121 & 1042 & 1065 & & 1113 & 1083 & 1059 & & 1045 & 1021 \\
\hline 12 & $a_{1}$ & & 1314 & 1275 & 1317 & & 1005 & 984 & 949 & & 1150 & 1114 \\
\hline 13 & $a_{1}$ & & 1494 & 1448 & 1491 & & 1294 & 1252 & 1268 & & 1413 & 1372 \\
\hline $8 a$ & $a_{1}$ & & 1637 & 1587 & 1635 & & 1577 & 1542 & 1507 & & 1665 & 1613 \\
\hline $20 \mathrm{a}$ & $a_{1}$ & & 3191 & 3121 & 3224 & & 3201 & 3133 & 3212 & & 3199 & 3128 \\
\hline 2 & $a_{1}$ & & 3212 & 3143 & 3248 & & 3223 & 3155 & 3266 & & 3217 & 3148 \\
\hline $10 \mathrm{a}$ & $a_{2}$ & & 249 & 239 & 247 & & 194 & 189 & 183 & 201 & 218 & 209 \\
\hline $16 a$ & $\mathrm{a}_{2}$ & & 597 & 573 & 588 & & 762 & 766 & 519 & 546 & 565 & 541 \\
\hline $17 \mathrm{a}$ & $\mathrm{a}_{2}$ & & 893 & 850 & 873 & & 1043 & 1107 & 788 & & 920 & 880 \\
\hline $17 \mathrm{~b}$ & $\mathrm{~b}_{1}$ & & 124 & 119 & 125 & 25 & 31 & 41 & 51 & 97 & 98 & 94 \\
\hline $10 \mathrm{~b}$ & $\mathrm{~b}_{1}$ & & 275 & 264 & 273 & 198 & 215 & 214 & 176 & 280 & 289 & 277 \\
\hline $16 \mathrm{~b}$ & $b_{1}$ & & 530 & 510 & 521 & 404 & 428 & 407 & 351 & 439 & 434 & 415 \\
\hline 4 & $b_{1}$ & & 717 & 684 & 675 & & 805 & 779 & 649 & 649 & 729 & 700 \\
\hline 11 & $b_{1}$ & & 792 & 754 & 772 & & 640 & 632 & 548 & 839 & 837 & 802 \\
\hline 5 & $b_{1}$ & & 968 & 922 & 944 & & 979 & 946 & 781 & & 1000 & 954 \\
\hline 15 & $\mathrm{~b}_{2}$ & & 212 & 204 & 208 & 63 & 64 & 67 & 154 & 213 & 221 & 212 \\
\hline $6 \mathrm{~b}$ & $\mathrm{~b}_{2}$ & & 509 & 494 & 501 & 443 & 451 & 463 & 439 & 367 & 386 & 369 \\
\hline 3 & $\mathrm{~b}_{2}$ & & 555 & 534 & 543 & & 511 & 501 & 492 & 489 & 539 & 522 \\
\hline $7 \mathrm{~b}$ & $\mathrm{~b}_{2}$ & & 1020 & 990 & 1014 & & 979 & 958 & 948 & 982 & 1018 & 986 \\
\hline $9 b$ & $\mathrm{~b}_{2}$ & & 1179 & 1088 & 1167 & & 1137 & 1128 & 1133 & & 1110 & 1087 \\
\hline $18 \mathrm{~b}$ & $b_{2}$ & & 1266 & 1226 & 1262 & & 1208 & 1171 & 1194 & & 1303 & 1259 \\
\hline 14 & $b_{2}$ & & 1322 & 1331 & 1424 & & 1380 & 1393 & 1456 & & 1354 & 1316 \\
\hline $19 \mathrm{~b}$ & $\mathrm{~b}_{2}$ & & 1503 & 1456 & 1495 & & 1441 & 1382 & 1381 & & 1548 & 1500 \\
\hline $8 b$ & $b_{2}$ & & 1626 & 1577 & 1623 & & 1477 & 1451 & 1680 & & 1381 & 1370 \\
\hline $20 \mathrm{~b}$ & $\mathrm{~b}_{2}$ & & 3206 & 3137 & 3242 & & 3207 & 3139 & 3215 & & 3214 & 3145 \\
\hline
\end{tabular}


Table 3 B3LYP/TZVPP calculated geometries of 1,3,2-DCFB

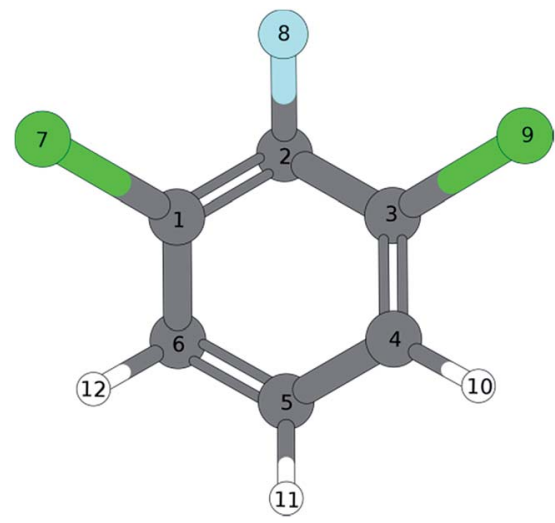

\begin{tabular}{|c|c|c|c|}
\hline B3LYP/TZVPP & $C_{2 \mathrm{v}}$ & $C_{2}$ & $C_{2 \mathrm{v}}$ \\
\hline Bond length [̊] & $\mathrm{S}_{0}$ & $\mathrm{~S}_{1}$ & $\mathrm{D}_{0}$ \\
\hline $\mathrm{C} 1-\mathrm{C} 2$ & 1.391 & 1.364 & 1.438 \\
\hline $\mathrm{C} 2-\mathrm{C} 3$ & 1.391 & 1.445 & 1.438 \\
\hline $\mathrm{C} 3-\mathrm{C} 4$ & 1.389 & 1.403 & 1.373 \\
\hline $\mathrm{C} 4-\mathrm{C} 5$ & 1.389 & 1.370 & 1.407 \\
\hline $\mathrm{C} 5-\mathrm{C} 6$ & 1.389 & 1.370 & 1.407 \\
\hline $\mathrm{C} 6-\mathrm{C} 1$ & 1.389 & 1.380 & 1.373 \\
\hline $\mathrm{C} 1-\mathrm{Cl} 7$ & 1.739 & 2.358 & 1.698 \\
\hline $\mathrm{C} 2-\mathrm{F} 8$ & 1.334 & 1.325 & 1.290 \\
\hline C3-Cl9 & 1.739 & 1.700 & 1.698 \\
\hline C4-H10 & 1.080 & 1.080 & 1.081 \\
\hline C5-H11 & 1.081 & 1.082 & 1.082 \\
\hline C6-H12 & 1.080 & 1.085 & 1.081 \\
\hline \multicolumn{4}{|l|}{ Bond angles $\left[{ }^{\circ}\right]$} \\
\hline $\mathrm{C} 1-\mathrm{C} 2-\mathrm{C} 3$ & 120.125 & 123.523 & 122.001 \\
\hline $\mathrm{C} 2-\mathrm{C} 3-\mathrm{C} 4$ & 119.972 & 119.825 & 118.077 \\
\hline $\mathrm{C} 3-\mathrm{C} 4-\mathrm{C} 5$ & 119.648 & 117.525 & 119.488 \\
\hline $\mathrm{C} 4-\mathrm{C} 5-\mathrm{C} 6$ & 120.635 & 120.436 & 122.869 \\
\hline C5-C6-C1 & 119.648 & 123.643 & 119.488 \\
\hline $\mathrm{C} 6-\mathrm{C} 1-\mathrm{C} 2$ & 119.972 & 115.049 & 118.077 \\
\hline $\mathrm{Cl} 7-\mathrm{C} 1-\mathrm{C} 2$ & 119.336 & 131.346 & 118.378 \\
\hline $\mathrm{C} 1-\mathrm{C} 2-\mathrm{F} 8$ & 119.938 & 121.023 & 118.996 \\
\hline $\mathrm{C} 4-\mathrm{C} 3-\mathrm{Cl} 9$ & 120.692 & 120.051 & 123.541 \\
\hline \multicolumn{4}{|l|}{ Dihedral angle $\left[{ }^{\circ}\right]$} \\
\hline Cl7-C1-C6-H12 & 0 & -0.018 & 0 \\
\hline $\mathrm{Cl} 7-\mathrm{C} 1-\mathrm{C} 2-\mathrm{F} 8$ & 0 & 0.016 & 0 \\
\hline Cl9-C3-C4-H10 & 0 & -0.005 & 0 \\
\hline
\end{tabular}

and $196 \mathrm{~cm}^{-1}$ to the modes $17 \mathrm{~b}^{1}$ and $17 \mathrm{~b}^{2}$ respectively seems appropriate. Assignments that are more tentative are the $16 \mathrm{~b}^{1}$ and $11^{1}$ to the bands at $439 \mathrm{~cm}^{-1}$ and $839 \mathrm{~cm}^{-1}$. The $\mathrm{a}_{2^{-}}$ symmetrical modes $10 \mathrm{a}^{1}$ and $16 \mathrm{a}^{1}$ are assigned to the weak bands at $201 \mathrm{~cm}^{-1}$ and $546 \mathrm{~cm}^{-1}$. With exception of $4^{1}$ all calculated frequencies are in good accordance with the experimentally determined ones.

Provided the validity of the $\Delta v=0$ propensity rule, the MATI spectrum obtained via the $\mathrm{S}_{1} 17 \mathrm{~b}^{1}$ mode ought to be characterized by a towering $17 \mathrm{~b}^{1}$ band. Contrary to expectations, the band $17 \mathrm{~b}^{1}$ could not be observed in the spectrum
Table 4 BP86/TZVPP calculated geometries of 1,3,2-DCFB

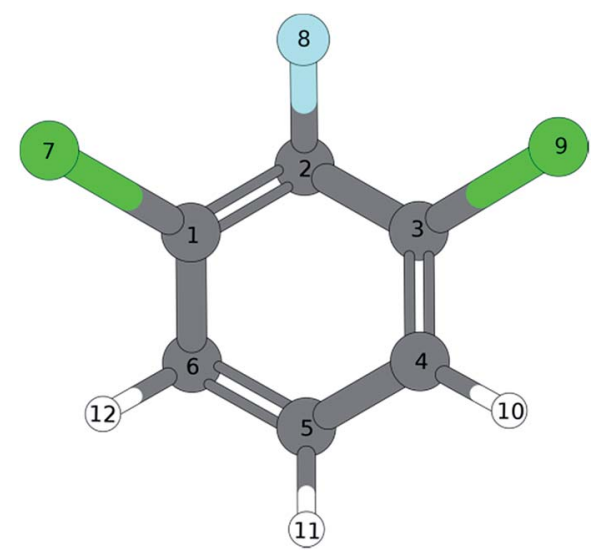

\begin{tabular}{|c|c|c|c|}
\hline BP86/TZVPP & $C_{2 \mathrm{v}}$ & $C_{2}$ & $C_{2 \mathrm{v}}$ \\
\hline Bond length $[\AA]$ & $\mathrm{S}_{0}$ & $\mathrm{~S}_{1}$ & $\mathrm{D}_{0}$ \\
\hline $\mathrm{C} 1-\mathrm{C} 2$ & 1.400 & 1.377 & 1.444 \\
\hline $\mathrm{C} 2-\mathrm{C} 3$ & 1.400 & 1.445 & 1.444 \\
\hline C3-C4 & 1.396 & 1.411 & 1.382 \\
\hline C4-C5 & 1.395 & 1.379 & 1.411 \\
\hline C5-C6 & 1.395 & 1.434 & 1.411 \\
\hline $\mathrm{C} 6-\mathrm{C} 1$ & 1.396 & 1.395 & 1.382 \\
\hline $\mathrm{C} 1-\mathrm{Cl} 7$ & 1.740 & 2.325 & 1.701 \\
\hline $\mathrm{C} 2-\mathrm{F} 8$ & 1.341 & 1.335 & 1.300 \\
\hline C3-Cl9 & 1.740 & 1.708 & 1.701 \\
\hline C4-H10 & 1.088 & 1.088 & 1.089 \\
\hline C5-H11 & 1.089 & 1.090 & 1.090 \\
\hline C6-H12 & 1.088 & 1.094 & 1.089 \\
\hline \multicolumn{4}{|l|}{ Bond angles $\left[{ }^{\circ}\right]$} \\
\hline $\mathrm{C} 1-\mathrm{C} 2-\mathrm{C} 3$ & 120.007 & 123.861 & 121.791 \\
\hline $\mathrm{C} 2-\mathrm{C} 3-\mathrm{C} 4$ & 120.019 & 120.100 & 118.195 \\
\hline $\mathrm{C} 3-\mathrm{C} 4-\mathrm{C} 5$ & 119.613 & 117.257 & 119.447 \\
\hline $\mathrm{C} 4-\mathrm{C} 5-\mathrm{C} 6$ & 120.728 & 120.361 & 122.865 \\
\hline C5-C6-C1 & 119.613 & 124.461 & 119.477 \\
\hline $\mathrm{C} 6-\mathrm{C} 1-\mathrm{C} 2$ & 120.019 & 113.959 & 118.195 \\
\hline $\mathrm{Cl} 7-\mathrm{C} 1-\mathrm{C} 2$ & 119.198 & 130.690 & 118.269 \\
\hline $\mathrm{C} 1-\mathrm{C} 2-\mathrm{F} 8$ & 119.938 & 121.023 & 118.996 \\
\hline C4-C3-Cl9 & 120.783 & 119.621 & 123.535 \\
\hline \multicolumn{4}{|l|}{ Dihedral angle $\left[{ }^{\circ}\right]$} \\
\hline $\mathrm{Cl} 7-\mathrm{C} 1-\mathrm{C} 6-\mathrm{H} 12$ & 0 & -0.030 & 0 \\
\hline $\mathrm{Cl} 7-\mathrm{C} 1-\mathrm{C} 2-\mathrm{F} 8$ & 0 & 0.038 & 0 \\
\hline Cl9-C3-C4-H10 & 0 & -0.006 & 0 \\
\hline
\end{tabular}

shown in Fig. 4. Instead, the spectrum shows the $9 a^{1}$ at 291 $\mathrm{cm}^{-1}$ as the most intensive resonance absorption. As can be seen from the correlation between the MATI spectra in Fig. 4, the first overtone $9 \mathrm{a}^{2}$ appears at $586 \mathrm{~cm}^{-1}$ as well. The signals at $419 \mathrm{~cm}^{-1}$ and $629 \mathrm{~cm}^{-1}$ are identified as the $6 \mathrm{a}^{1}$ and $1^{1}$ total symmetric modes. Obviously, the signals for the 11-vibration is broadened. Based on the MATI spectrum of the $0^{0}$ transition, we assigned this signal both to the $1^{1}$ and $4^{1}$ vibrations, the latter of which gives rise to the shoulder. The MATI spectrum obtained via the $\mathrm{S}_{1} 9 \mathrm{a}^{1}$ shows three prominent peaks: the $6 \mathrm{a}^{1}$, the $9 \mathrm{a}^{1} 6 \mathrm{a}^{1}$ and the $18 \mathrm{a}^{1}$. Without folding the spectrum with the laser 
Table 5 CC2/cc-pVTZ calculated geometries of 1,3,2-DCFB

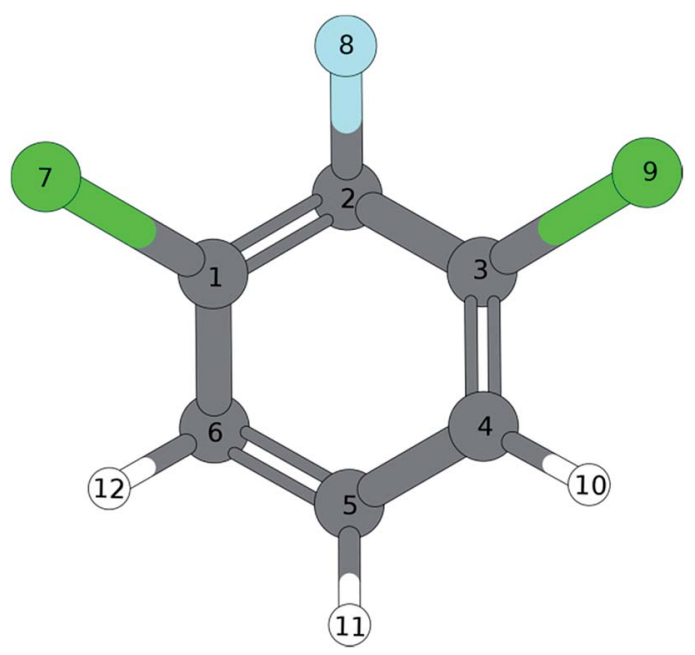

\begin{tabular}{|c|c|c|}
\hline BP86/TZVPP & $C_{2 \mathrm{v}}$ & $C_{2}$ \\
\hline Bond length $[\AA]$ & $\mathrm{S}_{0}$ & $\mathrm{~S}_{1}$ \\
\hline C1-C2 & 1.395 & 1.432 \\
\hline $\mathrm{C} 2-\mathrm{C} 3$ & 1.395 & 1.432 \\
\hline $\mathrm{C} 3-\mathrm{C} 4$ & 1.393 & 1.426 \\
\hline $\mathrm{C} 4-\mathrm{C} 5$ & 1.393 & 1.421 \\
\hline C5-C6 & 1.393 & 1.421 \\
\hline C6-C1 & 1.393 & 1.426 \\
\hline $\mathrm{C} 1-\mathrm{Cl} 7$ & 1.725 & 1.719 \\
\hline $\mathrm{C} 2-\mathrm{F} 8$ & 1.333 & 1.326 \\
\hline $\mathrm{C} 3-\mathrm{Cl} 9$ & 1.725 & 1.719 \\
\hline C4-H10 & 1.080 & 1.079 \\
\hline C5-H11 & 1.081 & 1.082 \\
\hline C6-H12 & 1.080 & 1.079 \\
\hline \multicolumn{3}{|l|}{ Bond angles $\left[{ }^{\circ}\right]$} \\
\hline $\mathrm{C} 1-\mathrm{C} 2-\mathrm{C} 3$ & 119.992 & 121.970 \\
\hline $\mathrm{C} 2-\mathrm{C} 3-\mathrm{C} 4$ & 120.078 & 118.706 \\
\hline C3-C4-C5 & 119.618 & 118.910 \\
\hline $\mathrm{C} 4-\mathrm{C} 5-\mathrm{C} 6$ & 120.617 & 122.532 \\
\hline C5-C6-C1 & 119.618 & 118.910 \\
\hline $\mathrm{C} 6-\mathrm{C} 1-\mathrm{C} 2$ & 120.078 & 118.706 \\
\hline $\mathrm{Cl} 7-\mathrm{C} 1-\mathrm{C} 2$ & 119.105 & 118.817 \\
\hline $\mathrm{C} 1-\mathrm{C} 2-\mathrm{F} 8$ & 120.004 & 119.015 \\
\hline $\mathrm{C} 4-\mathrm{C} 3-\mathrm{Cl} 9$ & 110.817 & 120.760 \\
\hline \multicolumn{3}{|l|}{ Dihedral angle $\left[{ }^{\circ}\right]$} \\
\hline Cl7-C1-C6-H12 & 0 & -17.842 \\
\hline $\mathrm{Cl} 7-\mathrm{C} 1-\mathrm{C} 2-\mathrm{F} 8$ & 0 & 17.222 \\
\hline Cl9-C3-C4-H10 & 0 & -17.842 \\
\hline
\end{tabular}

power, no absolute statement can be made in regards to the peak intensities. The three peaks are of nearly equal intensity (approx. 5\% difference), so it is hard to tell which one is the highest in intensity. Nevertheless it can be stated that in contrary to the predictions of the propensity rule, transitions to $6 a^{1}$ and $9 a^{1} 6 a^{1}$ are at least as same as intensive while the vertical transition into the $\mathrm{D}_{0} 9 \mathrm{a}^{1}$ state is scarcely visible in the spectrum. Nevertheless the mode 9a appears in a series of overtones $9 \mathrm{a}^{1} 6 \mathrm{a}^{1}\left(710 \mathrm{~cm}^{-1}\right), 9 \mathrm{a}^{1} 1^{1}\left(924 \mathrm{~cm}^{-1}\right)$ and $9 \mathrm{a}^{2} 6 \mathrm{a}^{1}\left(1003 \mathrm{~cm}^{-1}\right)$.
Table 6 B3LYP/TZVPP calculated geometries of 1,3,2-DFCB

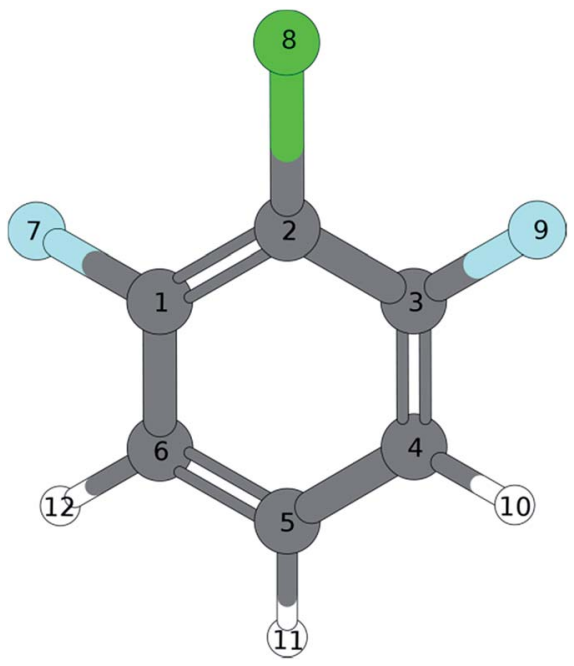

\begin{tabular}{|c|c|c|c|}
\hline B3LYP/TZVPP & $C_{2 \mathrm{v}}$ & $C_{2 \mathrm{v}}$ & $C_{2 \mathrm{v}}$ \\
\hline Bond length $[\AA]$ & $\mathrm{S}_{0}$ & $\mathrm{~S}_{1}$ & $\mathrm{D}_{0}$ \\
\hline $\mathrm{C} 1-\mathrm{C} 2$ & 1.393 & 1.365 & 1.440 \\
\hline $\mathrm{C} 2-\mathrm{C} 3$ & 1.393 & 1.365 & 1.440 \\
\hline $\mathrm{C} 3-\mathrm{C} 4$ & 1.384 & 1.444 & 1.365 \\
\hline C4-C5 & 1.389 & 1.384 & 1.409 \\
\hline C5-C6 & 1.389 & 1.384 & 1.409 \\
\hline $\mathrm{C} 6-\mathrm{C} 1$ & 1.384 & 1.444 & 1.365 \\
\hline C1-F7 & 1.340 & 1.326 & 1.309 \\
\hline $\mathrm{C} 2-\mathrm{Cl} 8$ & 1.729 & 2.361 & 1.665 \\
\hline C3-F9 & 1.340 & 1.326 & 1.309 \\
\hline $\mathrm{C} 4-\mathrm{H} 10$ & 1.081 & 1.081 & 1.081 \\
\hline C5-H11 & 1.081 & 1.080 & 1.082 \\
\hline C6-H12 & 1.081 & 1.081 & 1.081 \\
\hline
\end{tabular}

Bond angles $\left[{ }^{\circ}\right]$

$\mathrm{C} 1-\mathrm{C} 2-\mathrm{C} 3$

$\begin{array}{lll}117.528 & 111.693 & 118.393 \\ 121.919 & 126.328 & 120.838 \\ 118.997 & 118.962 & 118.528 \\ 120.640 & 117.726 & 122.876 \\ 118.997 & 118.962 & 118.528 \\ 117.528 & 126.328 & 120.838 \\ 118.843 & 120.164 & 117.338 \\ 121.236 & 124.155 & 120.803 \\ 119.237 & 113.508 & 121.823\end{array}$

Dihedral angle $\left[{ }^{\circ}\right]$

F7-C1-C6-H12

$\mathrm{F} 7-\mathrm{C} 1-\mathrm{C} 2-\mathrm{Cl} 8$

F9-C3-C4-H10

$\begin{array}{lrl}0 & 0.027 & 0 \\ 0 & -0.204 & 0 \\ 0 & -0.032 & 0\end{array}$

Remarkably, the spectrum exhibits a strong activity in $6 \mathrm{a}$ modes: the bands assigned to the modes $6 a^{1}$ and $9 a^{1} 6 a^{1}$ are among the three most intense bands in the spectrum. The $6 \mathrm{a}^{1}$ vibration shows progression activity $\left(6 \mathrm{a}^{1}\right.$ and $6 \mathrm{a}^{2}$ in the recorded range). In addition, the $6 \mathrm{a}^{1}$ mode contributes to overtone bands as already discussed above. The weak features at 97, 193 and $213 \mathrm{~cm}^{-1}$ have been assigned on the basis of our previous 
Table 7 BP86/TZVPP calculated geometries of 1,2,3-DFCB

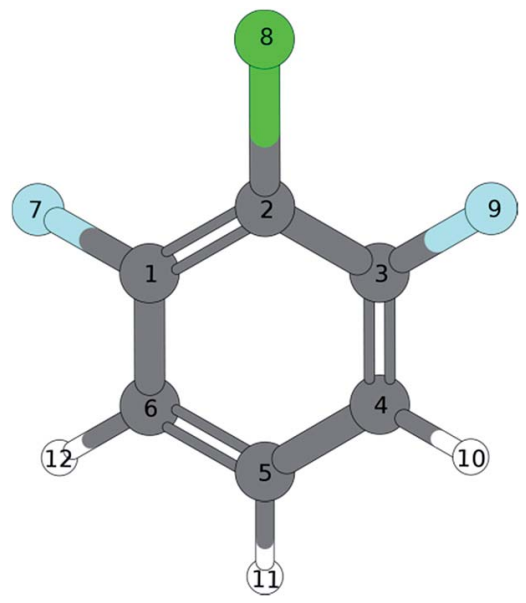

\begin{tabular}{|c|c|c|c|}
\hline BP86/TZVPP & $C_{2 \mathrm{v}}$ & $C_{2 \mathrm{v}}$ & $C_{2 \mathrm{v}}$ \\
\hline Bond length $[\AA]$ & $\mathrm{S}_{0}$ & $\mathrm{~S}_{1}$ & $\mathrm{D}_{0}$ \\
\hline $\mathrm{C} 1-\mathrm{C} 2$ & 1.401 & 1.378 & 1.446 \\
\hline $\mathrm{C} 2-\mathrm{C} 3$ & 1.401 & 1.378 & 1.446 \\
\hline $\mathrm{C} 3-\mathrm{C} 4$ & 1.391 & 1.446 & 1.374 \\
\hline $\mathrm{C} 4-\mathrm{C} 5$ & 1.396 & 1.391 & 1.414 \\
\hline C5-C6 & 1.396 & 1.391 & 1.414 \\
\hline $\mathrm{C} 6-\mathrm{C} 1$ & 1.391 & 1.446 & 1.374 \\
\hline C1-F7 & 1.348 & 1.337 & 1.318 \\
\hline $\mathrm{C} 2-\mathrm{Cl} 8$ & 1.730 & 2.332 & 1.671 \\
\hline C3-F9 & 1.348 & 1.337 & 1.318 \\
\hline $\mathrm{C} 4-\mathrm{H} 10$ & 1.089 & 1.089 & 1.089 \\
\hline C5-H11 & 1.089 & 1.087 & 1.090 \\
\hline C6-H12 & 1.089 & 1.089 & 1.089 \\
\hline \multicolumn{4}{|l|}{ Bond angles $\left[{ }^{\circ}\right]$} \\
\hline $\mathrm{C} 1-\mathrm{C} 2-\mathrm{C} 3$ & 117.514 & 110.326 & 118.508 \\
\hline $\mathrm{C} 2-\mathrm{C} 3-\mathrm{C} 4$ & 121.885 & 127.177 & 120.727 \\
\hline C3-C4-C5 & 118.999 & 118.870 & 118.543 \\
\hline $\mathrm{C} 4-\mathrm{C} 5-\mathrm{C} 6$ & 120.718 & 117.579 & 122.956 \\
\hline C5-C6-C1 & 118.999 & 118.870 & 118.543 \\
\hline $\mathrm{C} 6-\mathrm{C} 1-\mathrm{C} 2$ & 117.514 & 127.177 & 120.727 \\
\hline $\mathrm{F} 7-\mathrm{C} 1-\mathrm{C} 2$ & 118.763 & 119.276 & 117.392 \\
\hline $\mathrm{C} 1-\mathrm{C} 2-\mathrm{Cl} 8$ & 121.242 & 124.836 & 120.740 \\
\hline C4-C3-F9 & 119.349 & 113.548 & 121.870 \\
\hline \multicolumn{4}{|c|}{ Dihedral angle $\left[{ }^{\circ}\right]$} \\
\hline F7-C1-C6-H12 & 0 & 0.041 & 0 \\
\hline F7-C1-C2-Cl8 & 0 & -0.191 & 0 \\
\hline F9-C3-C4-H10 & 0 & -0.032 & 0 \\
\hline
\end{tabular}

studies $^{7,8}$ to the out-of-plane modes $17 \mathrm{~b}^{1}, 17 \mathrm{~b}^{2}$ and in-plane mode $15^{1}$.

\section{Discussion}

\subsection{1,3,2-DCFB}

Compared to electronic and cationic ground states the $17 \mathrm{~b}$ exhibits a drastically decreased frequency in the first electronic excited state (see Table 1). Such a frequency lowering suggests a geometrical distortion along the eigenvector of $17 \mathrm{~b}$ in going
Table 8 CC2/cc-pVTZ calculated geometries of 1,2,3-DFCB

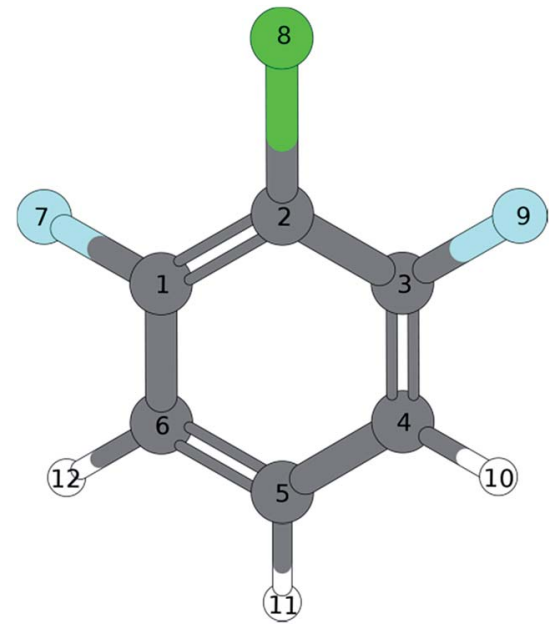

\begin{tabular}{|c|c|c|}
\hline B3LYP/TZVPP & $C_{2 \mathrm{v}}$ & $C_{2 \mathrm{v}}$ \\
\hline Bond length $[\AA]$ & $\mathrm{S}_{0}$ & $\mathrm{~S}_{1}$ \\
\hline C1-C2 & 1.396 & 1.4 \\
\hline $\mathrm{C} 2-\mathrm{C} 3$ & 1.396 & 1.41 \\
\hline $\mathrm{C} 3-\mathrm{C} 4$ & 1.387 & 1.4 \\
\hline $\mathrm{C} 4-\mathrm{C} 5$ & 1.394 & 1.4 \\
\hline C5-C6 & 1.394 & 1.407 \\
\hline C6-C1 & 1.387 & 1.431 \\
\hline C1-F7 & 1.339 & 1.337 \\
\hline $\mathrm{C} 2-\mathrm{Cl} 8$ & 1.716 & 1.825 \\
\hline C3-F9 & 1.339 & 1.337 \\
\hline $\mathrm{C} 4-\mathrm{H} 10$ & 1.080 & 1.8 \\
\hline C5-H11 & 1.081 & 1.3 \\
\hline C6-H12 & 1.080 & 1.0 \\
\hline
\end{tabular}

Bond angles $\left[^{\circ}\right]$

$\mathrm{C} 1-\mathrm{C} 2-\mathrm{C} 3$

$117.753 \quad 110.391$

$\mathrm{C} 2-\mathrm{C} 3-\mathrm{C} 4$

$121.786-125.833$

C3-C4-C5 $118.972 \quad 120.624$

$\begin{array}{lll}\mathrm{C} 4-\mathrm{C} 5-\mathrm{C} 6 & 120.732 & 116.095\end{array}$

C5-C6-C1 $118.972 \quad 120.624$

$\begin{array}{lll}\mathrm{C} 6-\mathrm{C} 1-\mathrm{C} 2 & 121.786 & 125.833\end{array}$

$\begin{array}{lll}\mathrm{F} 7-\mathrm{C} 1-\mathrm{C} 2 & 118.680 & 118.508\end{array}$

C1-C2-Cl8 $121.124 \quad 118.556$

$\begin{array}{lll}\text { C4-C3-F9 } & 119.534 & 115.651\end{array}$

Dihedral angle $\left[{ }^{\circ}\right]$

F7-C1-C6-H12 0.912

F7-C1-C2-Cl8 $\quad 0 \quad 46.945$

F9-C3-C4-H10 $\quad 0 \quad-0.912$

from $S_{0}$ to $S_{1}$ or from $D_{0}$ to $S_{1}$, respectively. As considered earlier by Tsuchiya et $a{ }^{1{ }^{14}}$ for difluorobenzene it is highly suggested that this phenomenon is the result of strong vibronic coupling between the $S_{1}$ and nearby states. But the most important indication for a such a distortion shows up in the MATI spectra via the electronic origin and, first and foremost, via the $17 \mathrm{~b}^{2}$. The latter exhibits a three-membered progression of the mode $17 \mathrm{~b}$. Not just that this progression shows a shift of the FranckCondon maximum between $S_{1}$ and $D_{0}$, the fact that the transition from $D_{0} 17 b^{1} \leftarrow S_{1} 17 b^{2}$ is favored could be interpreted as a 

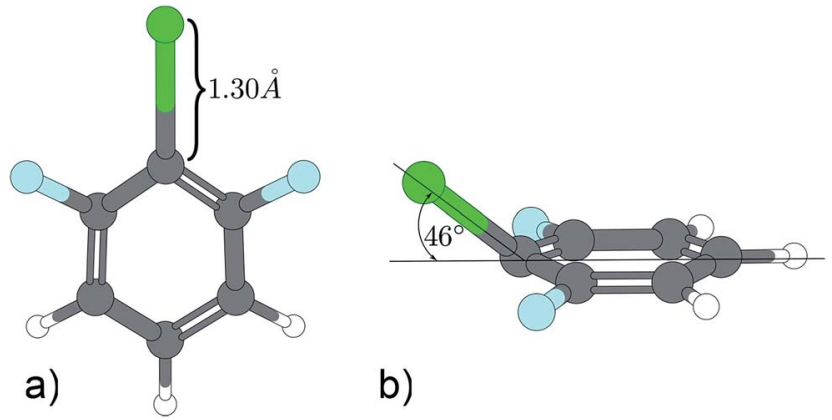

b)

Fig. 6 Excited state geometry of 1,3,2-DFCB obtained by different quantum mechanical methods. (a) TDDFT, (b) CC2.

replanarisation of the molecular geometry in going from $S_{1}$ to $\mathrm{D}_{0}$ along that mode.

Also during ionization via the vibrationless level of the first excited state, the transition $\mathrm{D}_{0} 17 \mathrm{~b}^{1} \leftarrow \mathrm{S}^{0}$ is clearly favored over $\mathrm{D}_{0} 0^{0} \leftarrow \mathrm{S}_{1} 0^{0}$ (see MATI via $0^{0}$ Fig. 2). A major role of the $17 \mathrm{~b}$ mode during ionization is aggravated by the fact the $17 \mathrm{~b}$ also appears as combination bands $\left(17 b^{1} 9 a^{1}\right.$ in each of the recorded MATI spectra, $17 \mathrm{~b}^{1} 6 \mathrm{~b}^{1}$ in the MATI via $17 \mathrm{~b}^{2}$ ). The strong activity of the mode $16 \mathrm{~b}^{1}$ in the MATI via $17 \mathrm{~b}^{2}$ and the general, unusual appearance of multiple other out-of-plane modes throughout the MATI spectra give rise to the assumption that the geometry in the $S_{1}$ is a product of a distortion along several modes. The CC2 computed geometry optimization seem to support the statements derived from the experimental data: the geometry shown in Fig. 5 is obviously not just the product of a distortion along a single (out-of-plane) normal mode (Table 2).

The quantum chemical calculations predict a $\mathrm{S}_{1}\left(\pi^{*} \leftarrow \pi\right)$ transition into the first excited state for 1,3,2-DCFB. However, due to $\sigma^{*}$-orbitals localized on the Halogen-Carbon bond, it is possible for modes of appropriate symmetry to induce coupling to $\left(\pi \sigma^{*}\right)$-states. In accordance with the assumption of a vibronic coupling effect we prevalently observed a substantial decrease in frequency comparing the $S_{0}$ state and the $S_{1}$ state of the neutral for formal forbidden modes with strong influence of halogen atoms on their displacement pattern. For the modes $15,6 \mathrm{~b}, 3$ ( $\mathrm{b}_{2}$ symmetry) and $16 \mathrm{a}$ ( $\mathrm{a}_{2}$ symmetry) we observed such a decrease.

The decrease in frequency for the modes $15,6 b, 3$ is explainable in accordance with the Herzberg-Teller (HT) effect. However, the frequency lowering of the symmetry allowed mode $17 \mathrm{~b}^{2}$ could not be described in terms of the HT effect in a sufficient way. It seems that the distortion along $17 \mathrm{~b}$ blurs the symmetry differences between the $\left(\pi \sigma^{*}\right)$ - and $\left(\pi \pi^{*}\right)$-states which would be an indication for a pseudo Jahn-Teller effect.

\subsection{1,3,2-DFCB}

In 1,3,2-DFCB the vibration 15 appears in the REMPI spectrum as a progression-forming and largely frequency lowered mode. Remarkably, the progression reveals a negative anharmonicity. The occurrence of the $15 a_{a} a_{2}$ symmetric mode is explained in terms of the Herzberg-Teller effect. Besides the mode 15, also the modes $6 \mathrm{a}$ and 9a exhibit a largely lowered frequency in the first excited state $S_{1}$. Both modes are likely to contribute in pseudo Jahn-Teller distortion in going from the electronic ground to excited state or from excited state to ionic ground state, respectively. This is seen from the different MATI spectra as well as the different calculated structures given in Tables 3-8. The MATI spectrum via the electronic origin exhibits a harmonic, three-membered progression of mode $9 \mathrm{a}\left(9 \mathrm{a}^{1}, 9 \mathrm{a}^{2}\right.$, $\left.9 a^{3}\right)$, whereby the band $9 a^{1}$ is almost as intense as the $0-$ 0 transition. Such a shift of the Franck-Condon maximum is a clear indication for a distortion along the eigenvector of this mode during ionization.

A similar situation is found in the MATI spectrum via $9 \mathrm{a}^{1}$. Here, in contradiction to the $\Delta v=0$ propensity rule, the transition into the $S_{1} 6 a^{1}$ state is the most favorable while the vertical transition into the $9 \mathrm{a}^{1}$ is scarcely observable. Nevertheless the mode $9 a$ is strongly present in overtones $\left(9 a^{1} 6 a^{1}, 9 a^{1} 1^{1}, 9 a^{2} 6 a^{1}\right)$. The geometry found by the TDDFT calculations (Fig. 6a; Tables 6 and 7) support the experimental findings in predicting a $C_{2 \mathrm{v}^{-}}$ symmetric structure distorted along the $6 \mathrm{a}$. The $\mathrm{CC} 2$ calculation suggests a 17b-like distorted structure (Fig. 6b; Table 8).

The CC2 calculation suggests a 17b-like distorted structure (Fig. 6b). Considering the vanishing low activity of $17 \mathrm{~b}$ in the MATI spectra, the suggestion seems incorrect. Nevertheless the substantial decrease in frequency for $6 \mathrm{a}^{1}$ and $9 \mathrm{a}^{1}$ comparing the $\mathrm{D}_{0}$ state and the $\mathrm{S}_{1}$ state is accurately reproduced by all quantum chemical methods employed. Comparing experimental and calculated results for 1,3,2-DFCB, the unusual, striking deviation (up to $49 \%$ ) for $\mathrm{a}_{1}$-symmetrical $\mathrm{S}_{1}$-frequencies was particularly noticeable. A poor reproduction of the molecular equilibrium structure in the $\mathrm{S}_{1}$ (wrong minimum on the PES) could be one possible explanation.

A contrary indication is the fact that we find very similar frequencies for widely differing structures predicted by TDDFT (planar structure) and CC2 method (out-of-plane-structure). The planar structure resembles the experimental observations well, but since all frequency analyses were performed in harmonic approximation, a strong anharmonicity for this particular vibrations could be another explanation for this findings.

\section{Conclusion}

Comparing the results from two compounds presented in this paper with results obtained from different isomeric trichlorobenzenes, ${ }^{1}$ the increasing number of fluorine atoms lead to a progressive decrease in some of the observed frequencies in going from $S_{0}$ to $S_{1}$ and from $D_{0}$ to $S_{1}$, respectively. This is especially true for modes with a strong fluorine participation in their vibrational pattern like 17b ( $c f$. Table 1). We interpreted this as a strong indication for an out-of-plane distortion during excitation or a replanarisation during ionization along the eigenvector of those modes. This phenomenon could be attributed to an above, bounding $\mathrm{S}\left(\pi \sigma^{*}\right)$ state which is stabilized by an increasing number of fluorine atoms. ${ }^{12}$ It can be concluded that the fluorine atoms contribute a significant share in form of $\sigma^{*} \leftarrow \pi$ character to the transition.

For 1,3,2-DCFB the quantum chemical calculations gave excitation energies (EE) of $5.06 \mathrm{eV}$ (B3LYP/TZVPP), $4.71 \mathrm{eV}$ 
(BP86/TZVPP) and $4.44 \mathrm{eV}$ (CC2/cc-pVTZ). The CC2 value reproduces the experimental value of $4.52 \mathrm{eV}$ with a deviation of $0.08 \mathrm{eV}$ best.

The experimental value for the ionization energy (IE) of 9.32 $\mathrm{eV}$ is underestimated by both DFT methods with $9.00 \mathrm{eV}$ (B3LYP/TZVPP) and $8.97 \mathrm{eV}$ (BP86/TZVPP). (The coupled cluster method CC2 is not suited for the ionic species!). In this case the frequency analysis performed by the CC2 method showed to be most appropriate to reproduce the experimental frequencies.

For 1,3,2-DFCB the quantum chemical calculations gave excitation energies (EE) of $5.23 \mathrm{eV}$ (B3LYP/TZVPP), $4.90 \mathrm{eV}$ (BP86/TZVPP) and $3.88 \mathrm{eV}$ (CC2/cc-pVTZ). The TDDFT value reproduces the experimental value of $4.64 \mathrm{eV}$ best, whereas BP86 underestimates and B3LYP overestimates the experimental value. Both DFT methods with $9.03 \mathrm{eV}$ (B3LYP/TZVPP) and $9.02 \mathrm{eV}$ (BP86/TZVPP) underestimate the experimental value for the ionization energy (IE) of $9.38 \mathrm{eV}$. Contrary to the 1,3,2 DCFB the frequency analysis performed by the DFT methods results in a better reproduction of the experimental frequencies for the 1,3,2 DFCB.

Furthermore the $S_{1} \leftarrow S_{0}$ electronic excitation energies (EE) and $\mathrm{D}_{0} \leftarrow \mathrm{S}_{0}$ adiabatic ionization energies (IE) could be determined very exactly:

$$
\begin{aligned}
& \mathrm{EE}(1,3,2-\mathrm{DFCB})=36460 \pm 2 \mathrm{~cm}^{-1}, \mathrm{IE}(1,3,2-\mathrm{DFCB})=75.242 \\
\pm & 6 \mathrm{~cm}^{-1} ; \\
& \mathrm{EE}(1,3,2 \text {-DCFB })=37449 \pm 2 \mathrm{~cm}^{-1}, \mathrm{IE}(1,3,2-\mathrm{DCFB})=75.627 \\
\pm & 6 \mathrm{~cm}^{-1} .
\end{aligned}
$$

\section{References}

1 F. Witte, R. Mikko, F. Gunzer and J. Grotemeyer, Mass analyzed threshold ionization (mati) spectroscopy of trichlorobenzenes via different intermediate vibrational states in the s1 state, Int. J. Mass Spectrom., 2011, 306, 129137, DOI: 10.1016/j.ijms.2010.10.002.

2 L. Yuan, C. Li, J. Lin, S. Yang and W. Tzeng, Mass analyzed threshold ionization spectroscopy of o-fluorophenol and omethoxyphenol cations and influence of the nature and relative location of substituents, Chem. Phys., 2006, 323, 429-438, DOI: 10.1016/j.chemphys.2005.10.004.

3 K. Müller-Dethlefs, M. Sander and E. W. Schlag, Two-colour photoionization resonance spectroscopy of NO: complete separation of rotational levels of $\mathrm{NO}^{+}$at the ionization threshold, Chem. Phys. Lett., 1984, 112, 291-294, DOI: 10.1016/0009-2614(84)85743-7.

4 L. Zhu and P. Johnson, Mass analyzed threshold ionization spectroscopy, J. Chem. Phys., 1991, 94(8), 5769-5771, DOI: 10.1063/1.460460.

5 K. Walter, U. Boesl and E. W. Schlag, Molecular ion spectroscopy: resonance-enhanced multiphoton dissociation spectra of the fluorobenzene cation, Chem. Phys. Lett., 1989, 162(4, 5), 261-268, DOI: 10.1016/00092614(89)87041-1.

6 G. Reiser, D. Rieger, T. G. Wright, K. Müller-Dethlefs and E. W. Schlag, Zero-kinetic-energy (ZEKE) photoelectron spectroscopy of p-difluorobenzene via different intermediate vibrational levels in the s1 state, J. Phys. Chem., 1993, 97, 4335-4343, DOI: 10.1021/j100119a015.

7 A. Gaber, M. Riese and J. Grotemeyer, Mass analyzed threshold ionization spectroscopy of $\mathrm{o}^{-}, \mathrm{m}-$, and $\mathrm{p}$ dichlorobenzenes. Influence of the chlorine position on vibrational spectra and ionization energy, J. Phys. Chem. A, 2008, 112, 425-434, DOI: 10.1021/jp074802t.

8 A. Gaber, M. Riese and J. Grotemeyer, Detailed analysis of the cation ground state of three dichlorobenzenes by mass analyzed threshold ionization spectroscopy, Phys. Chem. Chem. Phys., 2008, 10, 1168-1176, DOI: 10.1039/B715496H.

9 C. Weickhardt, R. Zimmermann, K. W. Schramm, U. Boesl and E. W. Schlag, Laser mass spectrometry of the di-, triand tetrachlorobenzenes: isomer-selective ionization and detection, Rapid Commun. Mass Spectrom., 1994, 8, 381384, DOI: $10.1002 / \mathrm{rcm} .1290080508$.

10 C. H. Kwon and M. S. Kim, One-photon mass-analyzed threshold ionization spectroscopy of 1,3,5trifluorobenzene: the Jahn-Teller effect and vibrational analysis for the molecular cation in the ground electronic state, J. Chem. Phys., 2004, 121(6), 2622-2629, DOI: 10.1063/1.1765655.

11 S. Sato, K. Ikeda and K. Kimura, Zeke photo electron spectroscopy and ab initio force-field calculation of 1,2,4,5tetrafluorobenzene, J. Electron. Spectrosc. Relat. Phenom., 1998, 88-91, 137-142, DOI: 10.1016/S0368-2048(97)00256-9.

12 M. Z. Zgierski, T. Fujiwara and E. C. Lim, Photophysics of aromatic molecules with low-lying pi sigma * states: fluorinated benzenes, J. Chem. Phys., 2005, 122(14), 144312, DOI: $10.1063 / 1.1873752$.

13 C. H. Kwon and M. S. Kim, Vacuum ultraviolet massanalyzed threshold ionization spectroscopy of hexafluorobenzene: the Jahn-Teller effect and vibrational analysis, J. Chem. Phys., 2004, 120(24), 11578, DOI: 10.1063/1.1753258.

14 Y. Tsuchiya, K. Takazawa, M. Fujii and M. Ito, Electronic spectra of $\mathrm{o}^{-}, \mathrm{m}-$, p-difluorobenzene cations: striking similarity in vibronic coupling between the neutral molecule and its cation, J. Phys. Chem., 1992, 96(1), 99104, DOI: 10.1021/j100180a022.

15 F. Gunzer and J. Grotemeyer, New features in the mass analysed threshold ionization (MATI) spectra of alkyl benzenes, Phys. Chem. Chem. Phys., 2002, 24, 5966-5972, DOI: $10.1039 / \mathrm{b} 208283 \mathrm{~g}$.

16 F. Gunzer and J. Grotemeyer, Enhancing of the signal-tonoise ratio in MATI spectra, Int. J. Mass Spectrom., 2003, 228, 921-931, DOI: 10.1016/S1387-3806(03)00195-7.

17 R. Ahlrichs, M. Bär, M. Häser, H. Horn and C. Kölmel, Electronic structure calculations on workstation computers: the program system turbomole, Chem. Phys. Lett., 1989, 162, 165-169, DOI: 10.1016/0009-2614(89) 85118-8.

18 M. v. Arnim and R. Ahlrichs, Geometry optimization in generalized natural internal coordinates, J. Chem. Phys., 1999, 111, 9183-9190, DOI: 10.1063/1.479510. 
19 M. Häser and R. Ahlrichs, Improvements on the direct SCF method, J. Comput. Chem., 1989, 10, 104-111, DOI: 10.1002/jcc.540100111.

20 O. Treutler and R. Ahlrichs, Efficient molecular numerical integration schemes, J. Chem. Phys., 1995, 102, 346-354, DOI: $10.1063 / 1.469408$.

21 (a) A. D. Becke, Density functional calculations of molecular bond energies, J. Chem. Phys., 1986, 84, 4524-4529, DOI: 10.1063/1.450025; (b) A. Becke, Density-functional exchange-energy approximation with correct asymptotic behavior, Phys. Rev. A: At., Mol., Opt. Phys., 1988, 38, 3098, DOI: 10.1103/PhysRevA.38.3098; (c) F. Weigend, M. Häuser, H. Patzelt and R. Ahlrichs, RI-MP2: optimized auxiliary basis sets and demonstration of efficiency, Chem. Phys. Lett., 1998, 294, 143-152, DOI: 10.1016/S0009-2614(98) 00862-8; (d) F. Weigend, A. Köhn and C. Hättig, Efficient use of the correlation consistent basis sets in resolution of the identity MP2 calculations, J. Chem. Phys., 2002, 116, 3175-3183, DOI: 10.1063/1.1445115.

22 G. Varsanyi and S. Szoke, Vibrational Spectra of Benzene Derivatives, Academic Press, New York, London, 1969.

23 E. B. Wilson, The normal modes and frequencies of vibration of the regular plane hexagon model of the benzene molecule, J. Phys. Rev., 1934, 41, 706-714, DOI: 10.1103/PhysRev.45.706.

24 J. Green, D. Harrison and W. Kynaston, Vibrational spectra of benzene derivatives-XI 1,3,5- and 1,2,3-trisubstituted compounds, Spectrochim. Acta, Part A, 1971, 27(6), 793-806, DOI: 10.1016/0584-8539(71)80158-7.

25 M. Mohraz, J. Maier and E. Heilbronner, $\mathrm{He}(\mathrm{I} \alpha)$ and $\mathrm{He}(\mathrm{II} \alpha)$ photoelectron spectra of fluorinated chloro- and bromobenzenes, J. Electron Spectrosc. Relat. Phenom., 1980, 19, 429-446, DOI: 10.1016/0368-2048(80)80063-6. 